blood in the right side of the heart and the veins, in consequence of the former possessing greater irritability and contractility than the latter. I also consider the exciting causes to have been gravitation and cold, occasioning the condition of the lung termed by Dr. Williams hypostatic, and that the proximate endocarditis, pericarditis, and pneumonia agonisantium (as thus termed by Laennec), were the effect of the struggle occasioned by the distention of the right side of the heart, and the obstruction of the right pulmonary artery, arising from its engorged capillaries.

The practical inference deducible from the above case is, I think, that no individual in a state of intoxication should be permitted to lie in any single posture for a long period without intermission, or in a cold place.

\section{FUNCTIONS OF THE LYMPHATIC SYSTEM.}

\section{To the Editor of ThE LANCET.}

Sir,-Dr. Carpenter has written to me a note in which he claims priority in the declaration of the new functions assigned to the lymphatic system, and has forwarded me several pages of the proof-sheets of his "Principles of Human Physiology," pub. lished twelve months since, which contain the enunciation of this doctrine.

I have already privately assured this gentleman that I had never seen his work, and bad not been made acquainted with his views in any manner, so that my originality is not affected.

Dr. Carpenter has freely and clearly stated the principle in question, and thus far I recognise his claim and give him credit for philosophical acuteness. He draws my attention to the following passage, as declaratory of the general principle :-

"It may be stated, then, as a general fact, that the function of the absorbent system is to take up and to convey into the circulating apparatus such substances as are capable of appropriation to the nutritive process, whether these substances be furnished by the external world or be derived from the disintegration of the organism itself."

The words printed in italics show that Dr. Carpenter believed that the waste matter of the system was capable of being reconverted into nutritive matter; a position, in my opinion, inconsistent with the laws of physiology, and altogether insusceptible of proof. I have avoided this view of the question on this account.

strongly pulsating umbilical cord, which was then divided betwixt them, I observed the arteries on the placental side of the cord divided, to continue pulsating for several moments subsequently.
My sole principle is, that the unorganised adipose matter receives the necessary changes, fitting it for organisation, in the lymphatic vessels. It is true that $D r$. Carpenter recognises the probability of the transformation of oily matter into albumen by the agency of the blood in the lactiferous system; and so also did Müller, although this physiologist failed to observe that which was apparent to Dr. Carpenter, namely, the analogy between the two systems of vessels. The principle, as announced by $\mathrm{Dr}$. Carpenter, rests entirely upon this analogy. The principle, as contended for by me, rests upon evidence more direct. I have endeavoured to prove what before could only be suspected.

The demonstration of this view, resting upon the constituents of the lymph itself, the changes undergone in the ovum, and in the application of the laws of metamorphosis, give me not only a claim to originality in the general principle, granted by Dr. Carpenter, but also to priority in the adoption of direct inductive argument. The announcement, also, that uric acid or its elements is the azotising principle, necessarily flows out of my mode of reasoning, and is wholly mine. I shall not dilate upon the importance of this principle, both physiologically and pathologically.

I have much satisfaction in remarking that Dr. Carpenter, with a quick apprehen. sion of its value, has considered that it adds much force to the doctrine first suggested by him that the blood was the means of effecting the changes in the lactiferous vessels; for after the withdrawal of ulic acid from the blood to perform this office, its remaining elements pass through the liver to be secreted in the form of bile, and "Liebig has shown that bile + urine $=$ animal flesh, or thereabouts."

This view, also, completes the chain of evidence $I$ have brought forward respecting the pathology of typhus; for if uric acid be not separated from the blood in the lactifer. ous vessels, owing to any morbid condition of these vessels, the blood will not be prepared for the formation of bile; the liver will, in consequence, suffer an arrest, or derangement of function, and uric acid and oily matter will appear more abundantly in the urine. Let me further add the probability that the red particles are mainly instrumental in the performance of these azotising processes.

Dr. Carpenter will doubtless be pleased to see the further application of the point which his discrimination made evident. The process of the conversion of oily matter into albumen is one of those important changes of which (to use the words of Dr. Carpenter) "we are yet entirely ignorant." If my exposition has contributed to render 
this process clear, I shall not have written in vain. I remain, Sir, your most obedient servant,

Enfield, March 7, 1843.

George Ross.

\section{THE}

\section{SPLEEN AND THE PLACENTA.}

\section{To the Editor of THE LANCET.}

SIR,--Allow me to furnish you with my answer to Dr. Way's remarks of last week, p. 823 .

Dr. Way cites, - against my observation that in the higher animals there is no anastomosis between arteries and veins,-the circulatory arrangement of lizards and tortoises. Also (which has nothing to do with the question) the abnormally patent foramen ovale in cyanosis. He seems to have forgotten to introduce the other abnormal deviation, namely, varicose aneurism. But as well might a surgeon attempt to practise the adbesion of mucous and serous membranes, as expect the middle coat of an artery to merge directly into that of a vein, in the higher animals.

The old experiment of bleeding a parent animal to death, and finding the foetus not exsanguineous, is quite compatible, also, with $m y$ statement. There is no reason why the foetus should, at once, send all its blood through the umbilical arteries, because the parent, when bled to death, ceases to furnish blood to the umbilical vein. The foetus is constantly receiving and constantly returning a proportion of its circulating fluid; because the former is cut off, that is no particular reason why the latter should overfow. To quote old authorities against my experiments is, in a small way, like accusing Copernicus of ignorance of the theories of Hipparchus and Ptolemy. The placenta is always gorged when thrown off in the natural way; and it seems that wax injeetions never permeate its capillaries under any circumstances. But I shall shortly have another opportunity of aiding this point by an experiment, of which, perhaps, none of $\mathrm{Dr}$. Way's authorities ever dreamt. I remain, Sir, your's ever truly,

Kennington, March 6, 1843 .

\section{Robert Stevens.}

\section{MEDICAL NEWS FROM THE EAST.}

\section{To the Editor of THE LANCET.}

SiR,-If I may judge from the interest now taken by the public in everything which relates to the progress of civilization and the important changes continually going on in the East, the following communication will be received by your readers with very pecu. liar satisfaction. It is the first of the kind which has been transmitted from the Levant, and is an earnest, I hope, of "better things to come."

We have the testimony of the most experienced travellers that, for many generations Syria, and Palestine, like most other parts of the Ottoman Empire, have been left to the tender mercies of charm-venders, miracle-mongers, adventurers, fakirs, and sorcerers, always ready to impose upon the credulity of the simple; and even in modern times, it is a well.known fact that, until lately, there has not been a single resident practitioner to be found (possessing the slightest claim to respectability) from Gaza to Antioch, from Hebron to the Haouran, or from Beyrout to Damascus, Homs, and Hamah. But there is now an English physician at Jerusalem (Dr. M'Gowan, who resides with the Protestant bishop); and in the summer of 1842 , Dr. Kerns, the first agent of the "Syrian Medical-Aid Association," also quitted the shores of England for "the land of the Patriarchs." This gentleman entered upon his philanthropic mission with humble confidence of success, though with some misgivings concerning the distracted state of the country and the deeply-rooted prejudices of the people, which, it was to be feared, might, at the outset, materially interrupt his labours. I am happy to say that he has succeeded beyond his most sanguine expectations, and this interesting and densely populated territory is now beginning to appreciate the efforts which are making for its relief. No sooner was it announced that an English physician had been sent to establish a dispensary at Beyrout, than numbers of the inhabitants flocked down to the coast, bringing with them the sick, the halt, and the blind, that he might "lay his hands on them and heal them."

Knowing, as I do, the deplorable condition of Syria and Palestine, having myself witnessed the eagerness with which professional aid is sought by all classes when once their confidence is established, and the unfeigned gratitude which the inhabitants evince for the most trifling alleviation of their sufferings, it is particularly gratifying to me to think that my own countrymen should be the first to associate in so good a cause, and that the pleasing office of declaring these good tidings has been entrusted to me by the committee.

Permit me, then, to lay before you the first report of our first medical agent in Syria, and when I tell you that Dr. Kerns has, by the blessing of Providence, himself relieved, in the course of three short months, under every disadvantage, 1297 of his suffering fellow-creatures, who were previously, in common with many thousands, without any resource to which they could apply, let the emergency be what it might, and that he has voluntarily contributed to their neces- 